Cite this: Chem. Sci., 2014, 5, 1844

Received 2nd February 2014

Accepted 5th February 2014

DOI: $10.1039 / \mathrm{c} 4 \mathrm{sc} 00360 \mathrm{~h}$

www.rsc.org/chemicalscience

\title{
Hyperbranched polydendrons: a new controlled macromolecular architecture with self-assembly in water and organic solvents $\uparrow$
}

\author{
Fiona L. Hatton, ${ }^{a}$ Pierre Chambon, ${ }^{a}$ Tom O. McDonald, ${ }^{a}$ Andrew Owen ${ }^{b}$ \\ and Steven P. Rannard*a
}

A new macromolecular architecture (hyperbranched polydendrons) is presented. Combining aspects of linear-dendritic hybrids, controlled radical polymerisation and branched vinyl polymerisation, the materials have very high molecular weight $\left(M_{\mathrm{w}}>1 \mathrm{MDa}\right)$ and surface functionality. Although dispersities are broad ( $\Theta$ up to 25 ) the structures behave with remarkable uniformity upon manipulation of solvent environment. Comparisons of conventional linear-dendritic hybrids and hyperbranched polydendrons are presented, including aspects of their synthesis. Under solvent exchange in organic media, a reversible self-assembly to form monodispersed nanoparticles (PDI as low as 0.013 ) is observed. Self-assembly and encapsulation is also observed during aqueous nanoprecipitation of the hyperbranched materials, with nanoparticle size (diameters from 60-140 nm) controlled through modification of precipitation conditions and the generation of the ideally branched dendrons at one end of each primary chain. The aqueous nanoparticles are highly stable and offer considerable opportunities for tailored functionality and future advanced applications.

\section{Introduction}

The global interest in macromolecular architecture has been driven over the last two and a half decades by advances in controlled polymer synthesis techniques, such as nitroxidemediated polymerisation, ${ }^{1}$ atom transfer radical polymerisation $(\text { ATRP })^{2}$ and reversible addition-fragmentation chain-transfer polymerisation (RAFT), ${ }^{1}$ allowing the accurate tailoring of chain chemistry, composition and degree of polymerisation. Additionally, the appreciation of branched structures such as hyperbranched polymers ${ }^{3}$ (Fig. 1A) and dendrimers ${ }^{4}$ (Fig. 1B) has led to a variety of chemistries, rivalling those available for linear polymers including: polyimines/polyamines, ${ }^{5}$ polyurethanes,,$^{6,7}$ polyethers, ${ }^{8}$ polyesters, ${ }^{9}$ polycarbonates, ${ }^{10}$ polyamides, ${ }^{11,12}$ polyamidoamines, ${ }^{13}$ and polycarbosilanes. ${ }^{14}$ Structure and function have collectively been iterated to develop potential advanced applications for polymers in areas as diverse as drug delivery, ${ }^{15}$ biology, ${ }^{16}$ sensors, ${ }^{17}$ energy storage ${ }^{17,18}$ and self-healing coatings. ${ }^{19}$

The control of chemistry and purity have allowed macromolecular science to embrace nanomaterials, establishing

${ }^{a}$ Department of Chemistry, University of Liverpool, Crown Street, L69 7ZD, UK. E-mail: srannard@liv.ac.uk

${ }^{b}$ Department of Molecular and Clinical Pharmacology, University of Liverpool, Block $H$, 70 Pembroke Place, Liverpool L69 3GF, UK

$\uparrow$ Electronic supplementary information (ESI) available: Materials, full experimental details and characterisation. See DOI: 10.1039/c4sc00360h
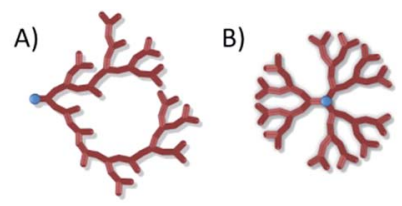

C)
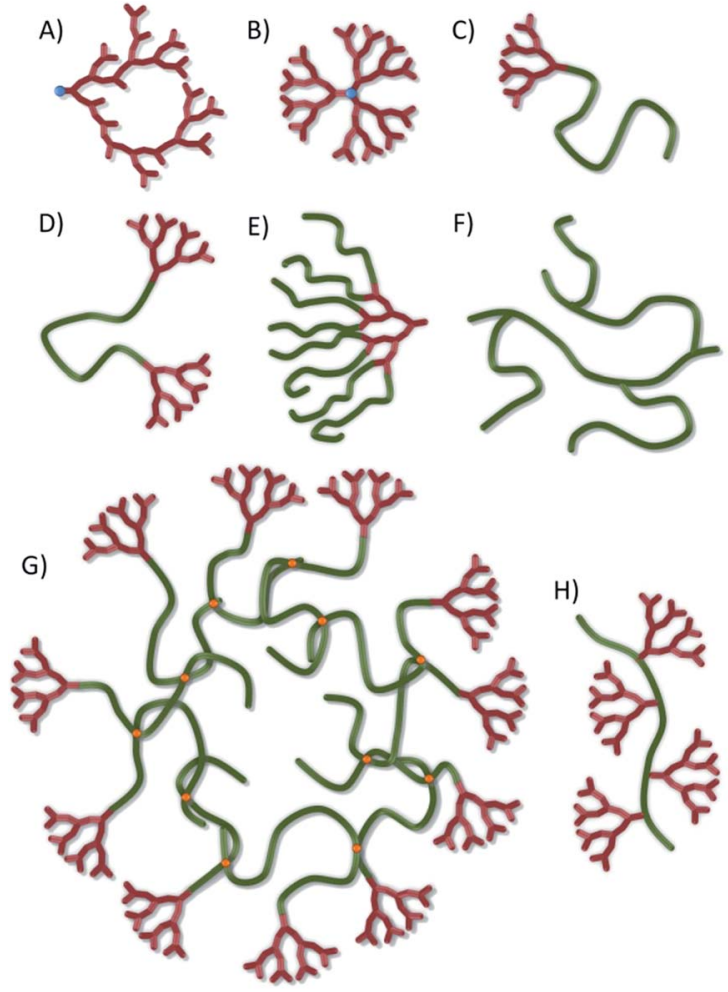

Fig. 1 Schematic representation of a range of macromolecular architectures: (A) hyperbranched polymer; (B) ideally branched dendrimer; (C) linear-dendritic (LD) hybrid; (D) DLD hybrid; (E) DLx hybrid; (F) self-condensed or grafted vinyl polymer; (G) hyperbranchedpolydendron; $(\mathrm{H})$ dendronised linear polymer. 
various self-assembled nanostructures ${ }^{20}$ from spherical solid nanoparticles ${ }^{21}$ to multi-compartment micelles, ${ }^{22,23}$ core-shell structures, ${ }^{24}$ vesicles/liposomes, ${ }^{25,26}$ rods $^{27}$ and worms. ${ }^{28}$ Arguably the most diverse organic nanomaterial studies have involved ideally-branched dendrimers. ${ }^{16,29,30}$ Dendritic polymer application $^{31}$ is maturing in nanomedicine ${ }^{32}$ and electronics, ${ }^{33}$ but, although dendrimers possess uniform molecular weight distributions and well defined shapes, the available size range is typically $<15 \mathrm{~nm},{ }^{34}$ although recent reports have described ideal, generation 13 polytriazine dendrimers with diameters of approximately $30 \mathrm{~nm}$ and molecular $8.4 \mathrm{MDa} \cdot{ }^{35}$ Considerable obstacles continue to exist for cost-effective applications of such materials including the synthetic complexity and molecular weight/physical size limitations.

Research spanning various chemical disciplines has also generated complex materials such as rotaxanes and catenanes, the mixture of cyclic structures and linear polymer chains, and the growing field of linear-dendritic hybrids where linear polymer chains are decorated either at the chain ends or side-chains with dendrons; fragments of dendrimers. Linear-dendritic polymer hybrids have now been synthesised in varying forms ${ }^{36 a}$ to create materials including one dendron at the end of a linear polymer (an LD hybrid; Fig. 1C), dendrons at both ends of a linear chain (a DLD hybrid; Fig. 1D), linear chains conjugated to the periphery of a dendron (a DLx hybrid, Fig. 1E) and dendrons at the centre of complex architectures with one linear chain attached to the focal point and either the same or different polymers synthesised from the peripheral dendron functionality (an LDLx hybrid). Micellar structures of amphiphilic lineardendritic copolymers $(30-70 \mathrm{~nm}),{ }^{9}$ and micelle aggregates (approximately $200 \mathrm{~nm}$ ), ${ }^{37}$ have been reported after association of relatively small building blocks.

The introduction of macromolecular complexity is often achieved at the expense of synthetic simplicity. Multiple iterative reactions are required to produce many such materials, with repeated isolation and purification steps and frequently the use of large reagent excesses. This limits access to these architectures to specialist research groups, preventing greater innovation and evaluation. The various reports of hyperbranched step-growth and vinyl polymerisations have attempted to simplify the synthesis of such materials but often structural fidelity or fine control is lost. In a range of cases, simple one-pot hyperbranched vinyl polymerisations ${ }^{38,39}$ have been shown to introduce nanoparticle formation, ${ }^{40}$ including shaped nanoparticles, ${ }^{41,42}$ with controllable stimuli responsive and surface active behaviour, ${ }^{43}$ even though the control of molecular weight and dispersity is somewhat sacrificed.

A key challenge is the identification of accessible chemistries that generate materials with novel architecture and uniform behaviour. Herein, we describe the first report of a novel approach that combines controlled radical polymerisation, hyperbranched vinyl polymerisation and linear dendritic hybrids to form a new polymer architecture, hyperbranched polydendrons (hyp-polydendrons). We have adopted this term as linear polymers that are decorated with dendrons (Fig. 1H) have been termed 'polydendrons' previously. ${ }^{44}$ Unlike branched vinyl polymers produced from self-condensing vinyl polymerisation $^{45}$ or grafting techniques ${ }^{46}$ (Fig. 1F), hyp-polydendrons (Fig. 1G) have two untethered ends on each primary chain of the branched architecture, with one chain end bearing an ideally branched dendron. The materials have unique structure and have been synthesised to very high molecular weights in a one-pot polymerisation strategy; as such these new materials offer novel opportunities. Moreover, we also describe the self-assembly of hyp-polydendrons to controllably form highly monodisperse, stable nanoparticles with control of size and chemistry; a highly surprisingly uniform behaviour from such polydisperse materials.

\section{Results and discussion}

Within our group, one-pot branched vinyl copolymerisation techniques have been shown to form nanoparticles in a single synthetic procedure ${ }^{41,42}$ via a concerted propagation and interchain branching of linear polymer chains using monofunctional monomers in the presence of low concentrations of bifunctional monomers. When used in conjunction with controlled radical polymerisation techniques, high molecular weight branched amphiphilic block copolymers have been formed that produce spherical nanoparticles when dialysed using water. ${ }^{41}$ The introduction of multi-functional initiators allowed dumbbell and clover-leaf nanoparticles to be formed. ${ }^{42}$ In this current study, we combine aspects of dendrimer and branched vinyl polymer strategies to simultaneously create linear-dendritic hybrid copolymers and introduce interchain branching to produce very high molecular weight complex unimolecular architectures in a one-pot controlled radical polymerisation. The hyp-polydendrons have been extensively characterised and their self-assembly in organic solvents and water is studied under various conditions.

\section{Dendron initiator synthesis and linear polymerisation studies}

One of the benefits of hyp-polydendrons is the ability to produce high molecular weight materials containing ideally branched dendritic chain ends, without the requirement for lengthy, iterative dendrimer or dendron syntheses. As such, we targeted low generation $\left(\mathbf{G}_{\mathbf{1}}-\mathbf{B r}\right.$ and $\left.\mathbf{G}_{2}-\mathbf{B r}\right)$ dendron ATRP initiators and have compared their efficiency with the simple commercial ethyl $\alpha$-bromoisobutyrate (EBiBr) initiator.

A straightforward synthesis (Scheme 1) was adopted for $\mathbf{G}_{\mathbf{1}^{-}}$$\mathbf{B r}$ and $\mathbf{G}_{2}-\mathbf{B r}$ using a symmetrical secondary alcohol 1,3dibenzyloxy-2-propanol, 1. $\mathbf{G}_{\mathbf{1}}-\mathbf{B r}$ was synthesised in a single reaction with $\alpha$-bromoisobutyryl bromide; $\mathbf{G}_{2}-\mathbf{B r}$ required the use of 1,1'-carbonyl diimidazole to form the imidazole carboxylic ester 2 and allow the selective formation of urethane links at the primary amino sites of diethylenetriamine $e^{6,47}$ to form the disubstituted product 3 . The ring opening of $\beta$-butyrolactone by the unreacted secondary amino functionality of 3 led to the synthesis of $\mathbf{4}$ containing a secondary hydroxyl which was readily reacted with $\alpha$-bromoisobutyryl bromide to yield $\mathbf{G}_{2}-\mathbf{B r}$. The synthesis of initiators and intermediates was confirmed by ${ }^{1} \mathrm{H}$ and ${ }^{13} \mathrm{C}$ nuclear magnetic resonance spectroscopy (NMR) and electrospray mass spectroscopy (see ESI, Fig. S1-S17†). 


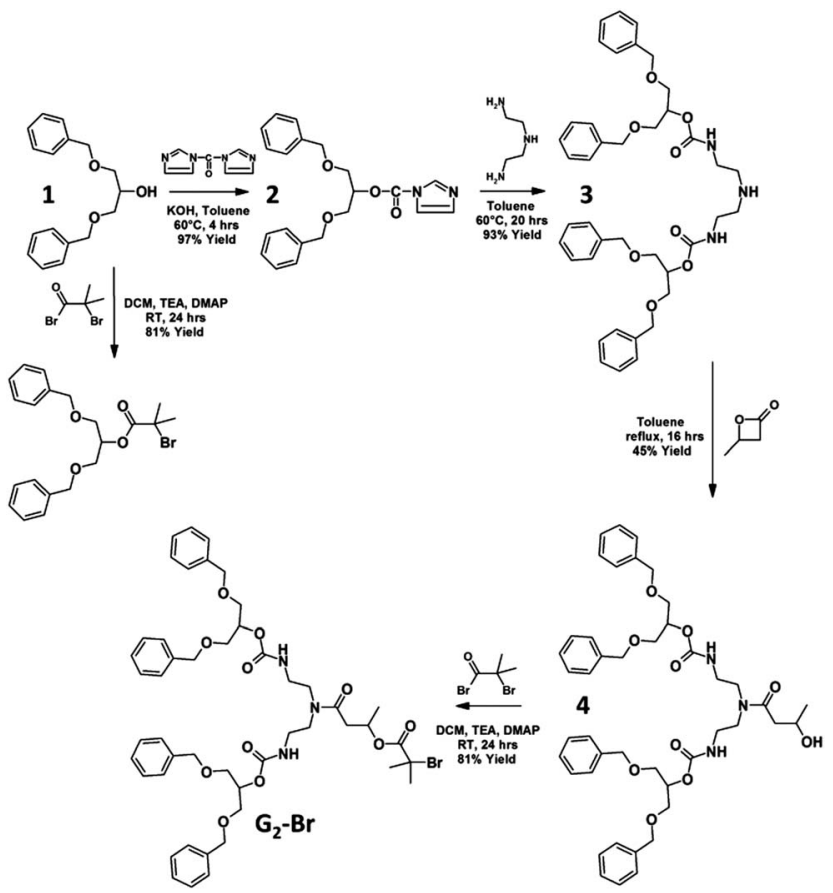

Scheme 1 Synthesis of first and second generation atom transfer radical polymerisation initiators used for hyp-polydendron synthesis.

We have previously used EBiBr to form linear and high molecular weight branched vinyl polymers through the ATRP of the commercial isomeric mixture of 2-hydroxypropyl methacrylate (HPMA) ${ }^{48}$ and similar conditions were employed in this study using $\mathrm{Cu}(\mathrm{I}) \mathrm{Cl}$ and 2,2'-bypyridyl as the catalytic system and methanol as the reaction solvent at a concentration of $50 \%$ $\mathrm{v} / \mathrm{v}$. The polymerisation of HPMA was targeted to number average degrees of polymerisation $\left(\mathrm{DP}_{n}\right)$ of 50 monomer units (ESI, Fig. S18 and S19†).

The targeted linear $\mathrm{p}\left(\mathrm{HPMA}_{50}\right)$, and linear-dendritic polymer hybrids $\mathrm{G}_{1}-\mathrm{p}\left(\mathrm{HPMA}_{50}\right)$ and $\mathrm{G}_{2}-\mathrm{p}\left(\mathrm{HPMA}_{50}\right)$, were readily synthesised at $30{ }^{\circ} \mathrm{C}$ (Scheme $2 \mathrm{~A}$ ) and allowed to polymerise to monomer conversions in excess of $99 \%$. Polymers of number average molecular weights $\left(M_{\mathrm{n}}\right)$ of $<15 \mathrm{kDa}$ and dispersity $(D)$ values of $<1.45$ were generated (Table 1 ), as determined by triple detection gel permeation chromatography (GPC), and excellent kinetic data was obtained, showing control of radical concentration throughout each polymerisation (Fig. 2).

Variation of the obtained $M_{\mathrm{n}}$ and $D$ values suggests differing initiator efficiencies, with $\mathbf{G}_{\mathbf{1}}-\mathbf{B r}$ appearing to be the most efficient, and possible termination by combination at the very high final monomer conversions (>99\%).

\section{Synthesis of hyperbranched-polydendrons}

The synthesis of a hyp-polydendron involves the polymerisation of a mixture containing a monofunctional monomer and a low concentration of bifunctional branching monomer. The branching monomer concentration must be maintained at a ratio with the initiator below an effective initiator : brancher of $1: 1$ to avoid gelation. This differs significantly from the reports

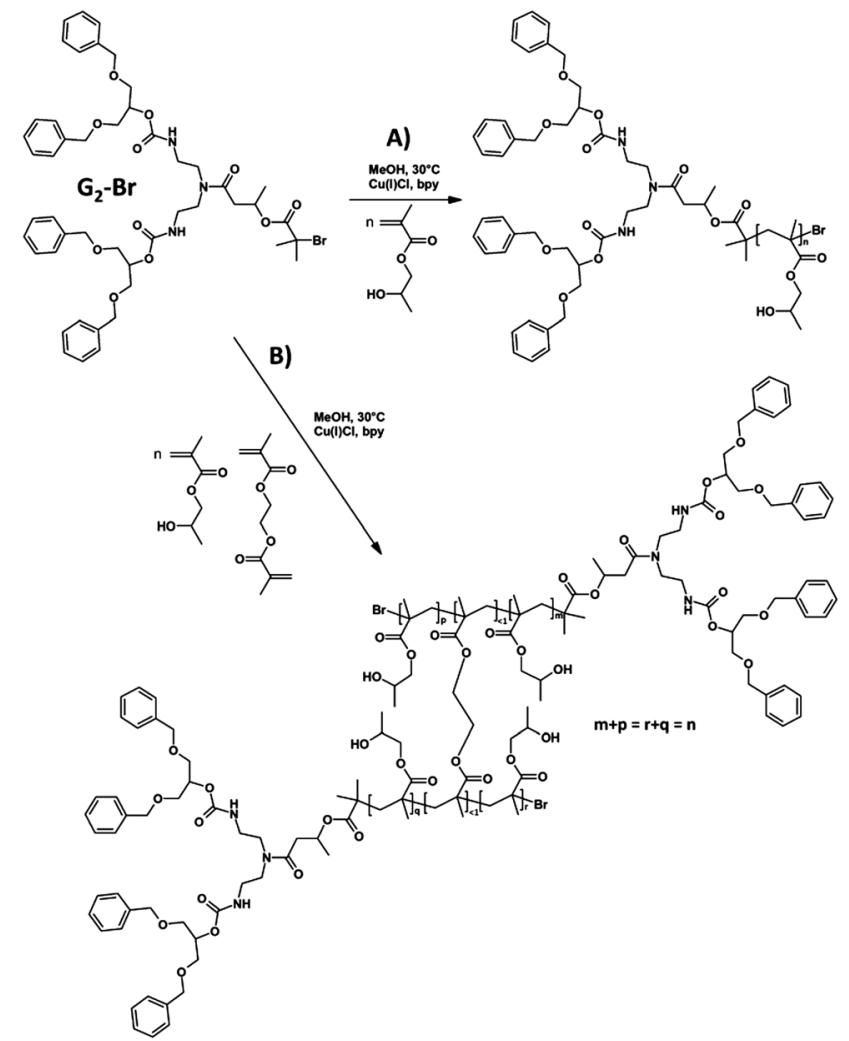

Scheme $2 \mathrm{Cu}$-catalysed ATRP Synthesis of (A) linear dendritic hybrids and (B) hyp-polydendrons using HPMA, EGDMA and $\mathrm{G}_{2}-\mathrm{Br}$. Scheme shows only two polymer chains conjoined for clarity. Many additional chains are combined into the branched architecture.

Table 1 Characterisation of linear-dendritic polymer hybrids and hyppolydendron synthesis using methanolic ATRP of HPMA

\begin{tabular}{|c|c|c|c|c|c|}
\hline \multirow[b]{2}{*}{ Target polymer } & \multicolumn{3}{|c|}{$\mathrm{GPC}^{a}(\mathrm{THF})$} & \multicolumn{2}{|c|}{ Calc. $\mathrm{DP}_{n}$} \\
\hline & $M_{\mathrm{n}}(\mathrm{Da})$ & $M_{\mathrm{w}}(\mathrm{Da})$ & 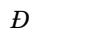 & GPC & ${ }^{1} \mathrm{H} \mathrm{NMR}{ }^{b}$ \\
\hline $\mathrm{p}\left(\mathrm{HPMA}_{50}\right)$ & 11250 & 13950 & 1.24 & 76.7 & - \\
\hline $\mathrm{p}\left(\mathrm{HPMA}_{50}-\mathrm{co}-\mathrm{EGDMA}_{0.8}\right)$ & 147100 & 928500 & 6.31 & - & - \\
\hline $\mathrm{G}_{1}-\left(\mathrm{HPMA}_{50}\right)$ & 9800 & 13000 & 1.33 & 65 & 55 \\
\hline $\mathrm{G}_{1}-\left(\mathrm{HPMA}_{50}-\mathrm{co}-\mathrm{EGDMA}_{0.8}\right)$ & 47250 & 1169000 & 24.74 & - & 57 \\
\hline $\mathrm{G}_{2}-\left(\mathrm{HPMA}_{50}\right)$ & 14400 & 20300 & 1.41 & 93.5 & 49 \\
\hline $\mathrm{G}_{2}-\left(\mathrm{HPMA}_{50}-\mathrm{co}-\mathrm{EGDMA}_{0.8}\right)$ & 90500 & 1304000 & 14.41 & - & 55 \\
\hline
\end{tabular}

of arms-first core-crosslinking using linear-dendritic hybrid macroinitiators. ${ }^{36 b}$

$\mathrm{EBiBr}, \mathbf{G}_{\mathbf{1}}-\mathbf{B r}$ and $\mathbf{G}_{\mathbf{2}}-\mathbf{B r}$ were therefore utilised (Scheme $2 \mathrm{~B}$ ) to initiate the polymerisation of HPMA in the presence of the branching monomer ethylene glycol dimethacrylate (EGDMA) with target $\mathrm{DP}_{n}$ values of 50 monomer units for the primary chains of the hyp-polydendron and an initiator : brancher ratio of $1: 0.8$ (ESI $\uparrow$ for experimental details). We have previously utilised EGDMA in this way to form highly branched p(HPMA) 
A)

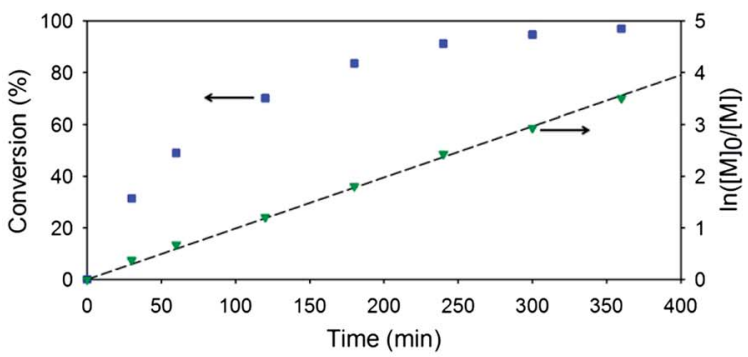

B)

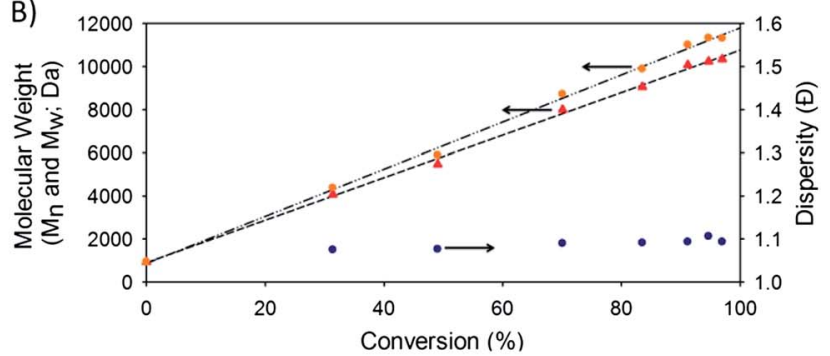

C)

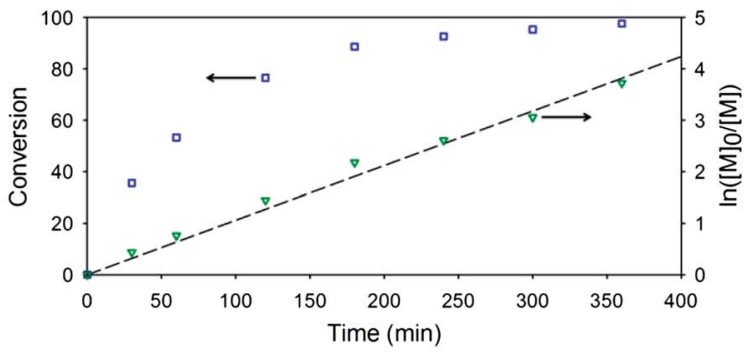

D)

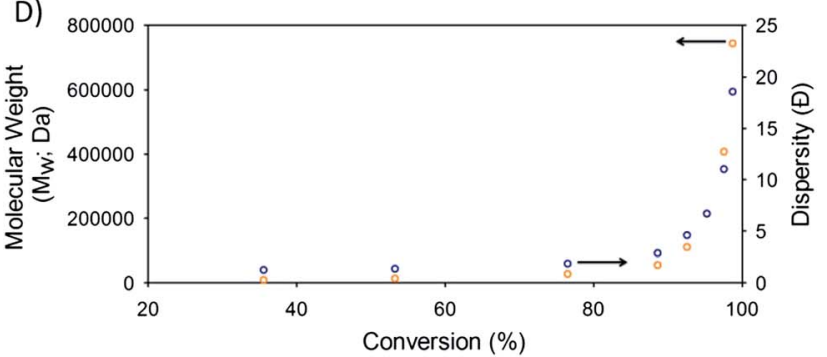

Fig. 2 Comparative studies of conversion vs. polymerisation time and the evolution of molecular weight with conversion for the methanolic ATRP of linear-dendritic hybrids and hyp-polydendrons using $\mathrm{G}_{2}-\mathrm{Br}$ to a targeted $\mathrm{DP}_{n}=50$ monomer units: $G_{2}-\left(H P M A_{50}\right)$ linear dendritic hybrid - (A) conversion vs. time plot (closed blue squares) and corresponding semi-logarithmic plot (closed green triangles), (B) overlaid $M_{w}$ (closed orange circles) and $M_{n}$ (closed red triangles) vs. conversion plots and corresponding $\boxminus$ vs. conversion (closed blue circles); hyppolydendron $G_{2}-\left(H P M A_{50}-C O-E G D M A_{0.8}\right)$ - (C) conversion vs. time plot (open blue squares) and corresponding semi-logarithmic plot (open green triangles); (D) overlaid $M_{\mathrm{w}}$ (open orange circles) vs. conversion plot and corresponding $\Theta$ vs. conversion (open blue circles).

and amphiphilic branched A-B block copolymers of oligoethylene glycol methacrylate and $n$-butyl methacrylate. ${ }^{41,42}$

In all cases, the presence of 0.8 equivalents of EGDMA, with respect to the initiator used, led to a considerable increase in the observed $M_{\mathrm{n}}$ and $M_{\mathrm{w}}$ values of the polymerisation and subsequent dispersities of the resulting polymers (Table 1). $M_{\mathrm{w}}$ values as high a $1.17 \mathrm{MDa}$ were seen for the $\mathrm{G}_{1}$-initiated hyppolydendrons and 1.30 MDa for $\mathrm{G}_{2}$-initiated materials. From a weight average perspective therefore, the recovered $\mathrm{G}_{1}$-initiated polymers comprised structures with approximately 90 primary chains and the $\mathrm{G}_{2}$-initiated polymers comprising approximately 65 primary chains. It was clear from the GPC chromatograms that materials of significantly higher molecular weight were also present (ESI, Fig. S18 and S19†).

Analysis of the kinetics of the ATRP reactions showed almost identical conversion $v s$. time and semi-logarithmic plots in the presence and absence of brancher, however, the development of $M_{\mathrm{n}}$ and $M_{\mathrm{w}}$ with conversion was noticeably different for the branched ATRP and non-linear at monomer conversions above $80 \%$ (Fig. 2). ${ }^{1} \mathrm{H}$ NMR analysis of the polymers after purification allowed a determination of the $\mathrm{DP}_{n}$ of the primary chains of the hyp-polydendron due to the clear resonance of the aromatic protons forming the peripheral groups of the dendron endgroup (ESI, Fig. S20广). Good correlation between the targeted number average chain length and that determined by ${ }^{1} \mathrm{H}$ NMR was observed.

\section{Solvent-driven hyperbranched-polydendron assembly}

Organic non-solvent addition: hexane-acetone mixtures. The six polymers shown in Table 1 were highly soluble in tetrahydrofuran (THF) and acetone; the $\mathrm{G}_{1}$ and $\mathrm{G}_{2}$ dendrons also showed considerable solubility in hexane, however, p(HPMA) is insoluble in this solvent. The effect of hexane addition to an acetone solution of each material was studied using solutions of each polymer at starting concentrations of $5 \mathrm{mg} \mathrm{mL}{ }^{-1}$. Addition of different volumes of hexane to the acetone solutions of $\mathrm{p}\left(\mathrm{HPMA}_{50}\right), \mathrm{G}_{1}-\left(\mathrm{HPMA}_{50}\right)$ and $\mathrm{G}_{2}-\left(\mathrm{HPMA}_{50}\right)$ linear polymers, led to the clear solutions becoming turbid, therefore measurements were conducted using dynamic light scattering (DLS) to determine particle size (ESI, Table S1 and Fig. S21 $\dagger)$. The EBiBr-initiated $\mathrm{p}\left(\mathrm{HPMA}_{50}\right)$ showed no appreciable light scattering until a hexane volume fraction $\left(\Phi_{\text {hexane }}\right)$ of 0.333 when a relatively broad distribution of particles with a $z$ average diameter $\left(D_{z}\right)$ of $350 \mathrm{~nm}(\mathrm{PDI}=0.21)$ could be observed. Addition of further hexane led to increases in particle size until an apparent plateau $\left(D_{z}\right.$ values varying between 560 and $580 \mathrm{~nm})$. Each measurement showed a narrow distribution $(\mathrm{PDI}=0.046-0.091)$ at $\Phi_{\text {hexane }}>0.500$.

The $\mathbf{G}_{\mathbf{1}}-\mathbf{B r}$ and $\mathbf{G}_{\mathbf{2}}-\mathbf{B r}$ initiated linear-dendritic hybrids underwent similar behaviour on addition of hexane, with initial measurements of particles observed at $\Phi_{\text {hexane }}=0.333$ and 0.286 respectively. Neither of the linear-dendritic hybrids led to a plateau of $D_{z}$ values with increasing hexane fraction and particles with $D_{z}$ up to $1.75 \mu \mathrm{m}\left(\mathrm{G}_{2}-\left(\mathrm{HPMA}_{50}\right) ; \Phi_{\text {hexane }}=0.750\right)$ and PDI values as high as $0.44\left(\mathrm{G}_{2}-\left(\mathrm{HPMA}_{50}\right) ; \Phi_{\text {hexane }}=0.333\right)$ were observed. Measurements using DLS are unreliable above 1 $\mu \mathrm{m}$ and, interestingly, the $\mathrm{G}_{2}-\left(\mathrm{HPMA}_{50}\right)$ material precipitated at $\Phi_{\text {hexane }}>0.750$; the only polymer in this series to do so at $\Phi_{\text {hexane }}$ values up to 0.800 .

The hyperbranched EBiBr-initiated polymer, $\mathrm{p}\left(\mathrm{HPMA}_{50^{-}} \mathrm{co}-\right.$ EGDMA $_{0.8}$ ), and the hyp-polydendrons within Table 1 were subjected to the same addition of non-solvent (Fig. 3 and ESI Table S1 $\dagger$ ) as discussed above. Measurable $D_{z}$ values were observed within the initial acetone solutions at values varying 
A)

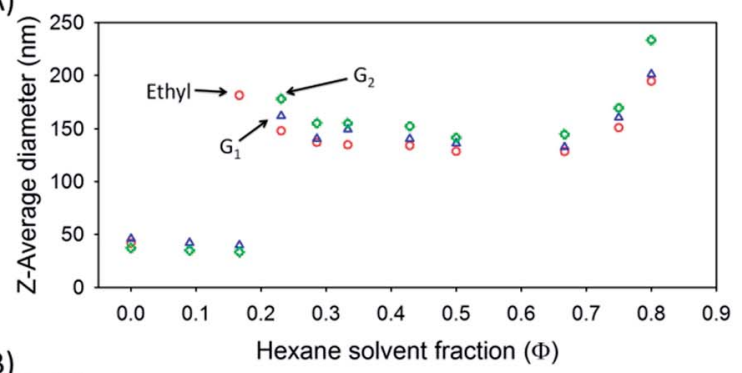

B)

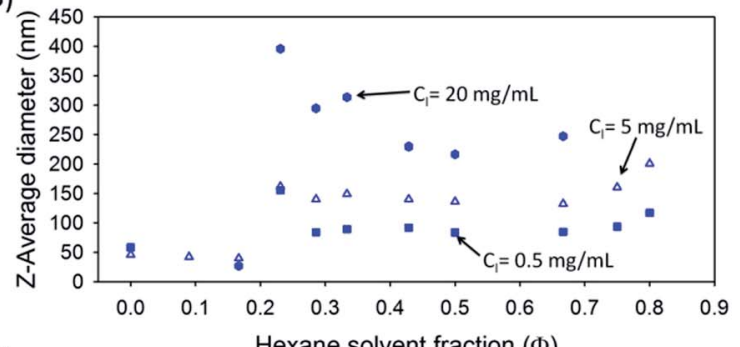

C)

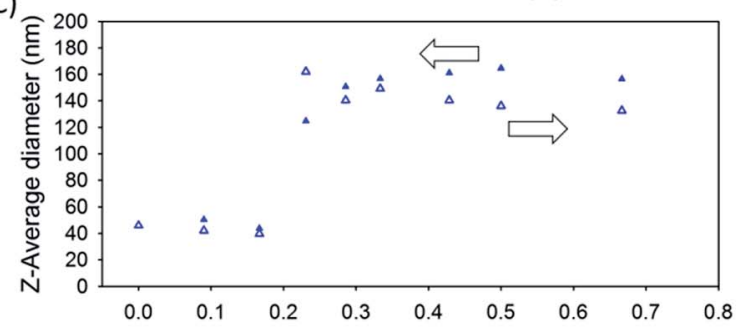

D)

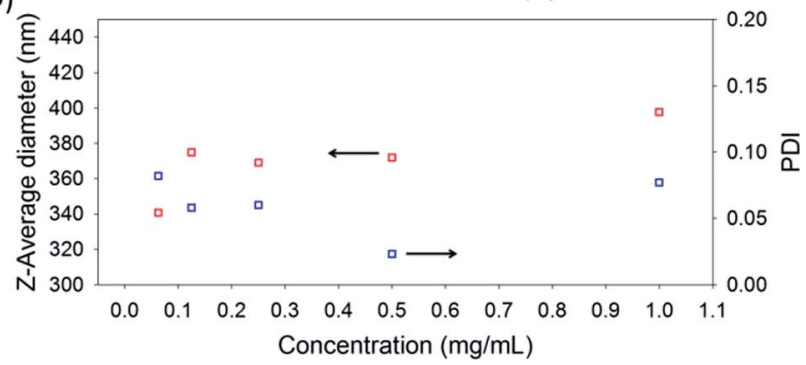

Fig. 3 Self-assembly of branched polymers on addition of hexane (bad solvent) to acetone (good solvent) solutions: (A) impact of hexane solvent fraction on $z$-average diameter for $\mathrm{p}\left(\mathrm{HPMA}_{50}-\mathrm{CO}-\mathrm{EGDMA}_{0.8}\right)$ (open red circles), $\mathrm{G}_{1}$ - $\left(\mathrm{HPMA}_{50}-\mathrm{CO}-\mathrm{EGDMA}_{0.8}\right.$ ) (open blue triangles) and $\mathrm{G}_{2}-\left(\mathrm{HPMA}_{50}-\mathrm{CO}-\mathrm{EGDMA}_{0.8}\right.$ ) (open green diamonds); (B) impact of initial solution concentration $\left(C_{1}\right)$ on self-assembly of $\mathrm{G}_{1}-\left(\mathrm{HPMA}_{50}-\mathrm{CO}-\right.$ $\left.\mathrm{EGDMA}_{0.8}\right) ;(\mathrm{C})$ reversible assembly of $\mathrm{G}_{1}-\left(\mathrm{HPMA}_{50}-\mathrm{Co}-\mathrm{EGDMA}_{0.8}\right)$ (arrows indicate direction of solvent addition); and (D) robustness of $\left.\mathrm{G}_{1}-\mathrm{HPMA}_{50}-\mathrm{CO}-\mathrm{EGDMA}_{0.8}\right)$ nanoparticles to dilution $\left(\Phi_{\text {hexane }}=\right.$ $0.800)$.

from $42 \mathrm{~nm}\left(\mathrm{p}\left(\mathrm{HPMA}_{50}-\mathrm{co}-\mathrm{EGDMA}_{0.8}\right)\right)$ to $46 \mathrm{~nm}\left(\mathrm{G}_{1}-\left(\mathrm{HPMA}_{50^{-}}\right.\right.$ co-EGDMA E.8 $\left._{0}\right)$ and $37 \mathrm{~nm}\left(\mathrm{G}_{2}-\left(\mathrm{HPMA}_{50}-\mathrm{co}-\mathrm{EGDMA}_{0.8}\right)\right)$ and PDI values from $0.4\left(\mathrm{p}\left(\mathrm{HPMA}_{50}-\mathrm{co}-\mathrm{EGDMA}_{0.8}\right)\right)$ to $0.38\left(\mathrm{G}_{2}-\left(\mathrm{HPMA}_{50^{-}}\right.\right.$ co-EGDMA $\left.\mathrm{E}_{0.8}\right)$ ) and $0.37\left(\mathrm{G}_{1}-\left(\mathrm{HPMA}_{50}-\mathrm{co}-\mathrm{EGDMA}_{0.8}\right)\right)$ (Fig. 3A).

Progressive increases in $\Phi_{\text {hexane }}$ led to corresponding decreases in the hyp-polydendron $D_{z}$ values with comparably broad dispersities. At a $\Phi_{\text {hexane }}=0.167$, the EBiBr-initiated hyperbranched polymer underwent a significant increase in size and decrease in PDI $\left(D_{z}=181 \mathrm{~nm}\right.$; PDI $\left.=0.055\right)$ and a similar increase in size and decrease in dispersity was seen for the hyp-polydendrons at $\Phi_{\text {hexane }}=0.231\left(\mathrm{G}_{1}-\left(\mathrm{HPMA}_{50}-\mathrm{co}-\right.\right.$ EGDMA $\left._{0.8}\right), \quad D_{z}=162 \mathrm{~nm}$, PDI $=0.021 ; \mathrm{G}_{2}-\left(\mathrm{HPMA}_{50}-\mathrm{co}-\right.$ EGDMA $\left._{0.8}\right), D_{z}=178 \mathrm{~nm}$, PDI $=0.018$ ) (Fig. 3A). Further addition of non-solvent for the p(HPMA) core architectures, up to $\Phi_{\text {hexane }}=0.667$, generated a steady but small decrease in $D_{z}$ for all hyperbranched materials studied, with the hyp-polydendron bearing the $\mathrm{G}_{2}$ dendron being the largest under all solvent conditions and the $\mathrm{EBiBr}$ initiated hyperbranched polymer consistently forming the smallest nanoparticles; in all cases the PDI values remained $<0.075$. At $\Phi_{\text {hexane }}$ between 0.667 and 0.800 , the nanoparticles from each material started again to increase in size whilst maintaining their order of size and low PDI values. The largest nanoparticle formed using this process had a $D_{z}=230 \mathrm{~nm}$ and PDI $=0.097\left(\mathrm{G}_{2}-\mathrm{HPMA}_{50}-\mathrm{co}-\right.$ EGDMA $\left.\left._{0.8}\right), \Phi_{\text {hexane }}=0.800\right)$.

The impact of the concentration of polymer in the initial acetone solution, prior to hexane addition, was studied using $0.5 \mathrm{mg} \mathrm{mL}^{-1}, 5 \mathrm{mg} \mathrm{mL}^{-1}$ and $20 \mathrm{mg} \mathrm{mL}^{-1}$ acetone solutions of the $\mathrm{G}_{1}-\left(\mathrm{HPMA}_{50}-\mathrm{co}-\mathrm{EGDMA}_{0.8}\right)$ hyp-polydendron (Fig. 3B). The observed large increases in $D_{z}$ at a $\Phi_{\text {hexane }}=0.231$ were generally followed by a subsequent decrease until $\Phi_{\text {hexane }}=0.500$. At values above this solvent ratio, the particles derived from the 20 $\mathrm{mg} \mathrm{mL} \mathrm{m}^{-1}$ starting concentration rapidly increased in size and subsequently precipitated. The lower polymer concentrations proceeded to $\Phi_{\text {hexane }}=0.667$ with an increase observed on addition of further hexane up to $\Phi_{\text {hexane }}=0.800$. Across the samples after $\Phi_{\text {hexane }}=0.231$, the low initial concentration of hyp-polydendron of $0.5 \mathrm{mg} \mathrm{mL} \mathrm{m}^{-1}$ gave consistently the smallest nanoparticles ( $D_{z}$ as low as $84 \mathrm{~nm}$ ) and the highest initial concentration of $20 \mathrm{mg} \mathrm{mL}^{-1}$ gave the largest nanoparticles $\left(D_{z}\right.$ as high as $396 \mathrm{~nm})$. After $\Phi_{\text {hexane }}=0.286$, PDI values varied from $<0.175$ across the sample starting at $20 \mathrm{mg} \mathrm{mL}^{-1}$, to $<0.075$ for materials generated from an initial concentration of $5 \mathrm{mg} \mathrm{mL}^{-1}$ and $<0.145$ for particles from the $0.5 \mathrm{mg} \mathrm{mL}^{-1}$ acetone solution.

The reversibility of the assembly into nanoparticles was also studied by preparing nanoparticles of the $\mathrm{G}_{1}-\mathrm{HPMA}_{50}-\mathrm{co}$ $\mathrm{EGDMA}_{0.8}$ ) hyp-polydendron (initial concentration (acetone) $=5$ $\left.\mathrm{mg} \mathrm{mL}{ }^{-1}\right)$ directly at a $\Phi_{\text {hexane }}=0.667\left(D_{z}=157 \mathrm{~nm}, \mathrm{PDI}=\right.$ 0.064 ) and slowly adding more acetone to decrease the hexane volume fraction (Fig. 3C). With the steady decrease in $\Phi_{\text {hexane }}$ a small increase in size was initially seen, but $D_{z}$ values only varied between $161 \mathrm{~nm}$ and $151 \mathrm{~nm}$ over a range of $\Phi_{\text {hexane }}$ from 0.667 to 0.286 . Addition of further acetone led to a considerable decrease to $125 \mathrm{~nm}\left(\Phi_{\text {hexane }}=0.231\right)$ and then a sharp decrease to $44 \mathrm{~nm}$ at $\Phi_{\text {hexane }}=0.167$. The addition of a good solvent, therefore, led to the disassembly of the nanoparticles at the same ratio of acetone-hexane required to initiate assembly. To establish whether the reversible phenomenon was driven by dilution, nanoparticles of the $\left.\mathrm{G}_{1}-\mathrm{HPMA}_{50}-\mathrm{co}-\mathrm{EGDMA}_{0.8}\right)$ hyppolydendron (generated directly at a concentration of $1 \mathrm{mg}$ $\mathrm{mL}^{-1}$ and a $\Phi_{\text {hexane }}=0.800 ; 5 \mathrm{mg} \mathrm{mL}^{-1}$ initial acetone concentration) were diluted with various volumes of an acetone-hexane mixture of identical composition (Fig. 3D). Across a 16-fold dilution, the nanoparticles were particularly robust and maintained both size and dispersity.

A direct comparison of the DLS analysis of the lineardendritic hybrids and the branched polymers are shown in 
Table 2 Comparison of linear-dendritic polymer hybrid and hyppolydendron self-assembly at $\Phi_{\text {hexane }}=0.800\left(5 \mathrm{mg} \mathrm{mL}^{-1}\right.$ initial acetone concentration)

\begin{tabular}{|c|c|c|}
\hline Polymer & $D_{z}^{a}$ & $\mathrm{PDI}^{a}$ \\
\hline $\mathrm{p}\left(\mathrm{HPMA}_{50}\right)$ & 488 & 0.127 \\
\hline $\mathrm{p}\left(\mathrm{HPMA}_{50^{-}}-\mathrm{co}-\mathrm{EGDMA}_{0.8}\right)$ & 301 & 0.033 \\
\hline $\mathrm{G}_{1}-\left(\mathrm{HPMA}_{50}\right)$ & 426 & 0.212 \\
\hline $\mathrm{G}_{1}-\left(\mathrm{HPMA}_{50}-\mathrm{co}-\mathrm{EGDMA}_{0.8}\right)$ & 294 & 0.093 \\
\hline $\mathrm{G}_{2}-\left(\mathrm{HPMA}_{50}\right)$ & $-^{b}$ & $-^{b}$ \\
\hline $\mathrm{G}_{2}-\left(\mathrm{HPMA}_{50}-\mathrm{co}-\mathrm{EGDMA}_{0.8}\right)$ & 356 & 0.013 \\
\hline
\end{tabular}

${ }^{a}$ As measured by dynamic light scattering. ${ }^{b}$ Linear $\mathrm{G}_{2}-\left(\mathrm{HPMA}_{50}\right)$ precipitated under these conditions.

Table 2 at a fixed $\Phi_{\text {hexane }}=0.800$ and generated from an initial concentration in acetone of $5 \mathrm{mg} \mathrm{mL}{ }^{-1}$. As can be seen, the branched materials produce much smaller nanoparticles with considerably lower PDI values in all cases.

Hyp-polydendron self-assembly via nanoprecipitation of THF solutions into water. We have previously shown the advantages of the hyperbranched $\mathrm{p}$ (HPMA) in the formation of aqueous nanoparticles through simple nanoprecipitation techniques. ${ }^{48 a}$ The impact of the initial polymer concentration $\left(C_{\mathrm{I}}\right)$ and the final concentration of the polymer nanoparticles in water $\left(C_{\mathrm{F}}\right)$ was demonstrated and ranges of stable nanoparticles from 60-800 nm were readily formed.

To investigate the aqueous nanoprecipitation of hyp-polydendrons, a similar study was undertaken using a rapid addition of varying volumes of polymer-THF solutions $\left(10 \mathrm{mg} \mathrm{mL}^{-1}\right.$ or $\left.5 \mathrm{mg} \mathrm{mL}{ }^{-1}\right)$ into 5 or $10 \mathrm{~mL}$ of water $\left(30^{\circ} \mathrm{C}\right)$, using the lineardendritic hybrids and the branched polymers (ESI $\dagger$ for experimental details). Each nanoparticle dispersion formed was stirred overnight at ambient temperature to remove the THF and generate aqueous nanoparticle dispersions ranging from $2 \mathrm{mg}$ $\mathrm{mL}^{-1}$ to $0.05 \mathrm{mg} \mathrm{mL}^{-1}$. As seen previously with linear $\mathrm{p}\left(\mathrm{HPMA}_{50}\right)$, the linear-dendritic hybrids underwent a selfassembly to form nanoparticles, however, the dispersions were not stable, showing increases in $D_{z}$ and PDI over time with visible precipitate over a small number of days. The branched $\mathrm{p}\left(\mathrm{HPMA}_{50}\right.$-co-EGDMA $\left.{ }_{0.8}\right)$ generated nanoparticles with $D_{z}$ values between 60 and $85 \mathrm{~nm}$ and PDI values ranging from 0.111 to 0.216 however the hyp-polydendrons displayed a wider range of sizes (60-135 nm) with lower PDI values (as low as 0.064). In all cases, the nanoparticles formed from $\mathrm{G}_{2}-\mathrm{HPMA}_{50}-\mathrm{co}$ EGDMA $\left._{0.8}\right)$ were larger than those derived from $\mathrm{G}_{1}-\left(\mathrm{HPMA}_{50}-\mathrm{co}\right.$ EGDMA $_{0.8}$ ) under identical conditions, and showed much lower dispersities (Table 3). Those formed from $\mathrm{p}\left(\mathrm{HPMA}_{50}-\mathrm{Co}\right.$ EGDMA $_{0.8}$ ) were similar in size or smaller than nanoparticles formed from $\mathrm{G}_{1}-\left(\mathrm{HPMA}_{50}-\mathrm{co}-\mathrm{EGDMA}_{0.8}\right)$, displaying the same overall trend in nanoparticle sizes that were seen when hexane was added to acetone solutions: ethyl $<\mathrm{G}_{1}$ dendron $<\mathrm{G}_{2}$ dendron (Fig. 3A).

The aqueous nanoparticles generated from all branched polymers were extremely stable; those from hyp-polydendrons still showed monomodal size distributions $\left(D_{z}<100 \mathrm{~nm}\right)$ with
Table 3 Aqueous nanoprecipitation of hyp-polydendrons from THF at varying initial solvent concentrations and dilution factors

\begin{tabular}{|c|c|c|c|c|c|}
\hline \multirow[b]{2}{*}{ Polymer } & \multicolumn{2}{|c|}{$\begin{array}{l}\text { Concentration } \\
\left(\mathrm{mg} \mathrm{mL} L^{-1}\right)\end{array}$} & \multirow[b]{2}{*}{$\begin{array}{l}\text { Dilution } \\
\text { factor }\left(C_{\mathrm{F}} / C_{\mathrm{I}}\right)\end{array}$} & \multirow[b]{2}{*}{$\begin{array}{l}D_{z}^{c} \\
(\mathrm{~nm})\end{array}$} & \multirow[b]{2}{*}{$\mathrm{PDI}^{c}$} \\
\hline & $\begin{array}{l}\text { Initial }^{a} \\
\left(C_{\mathrm{I}}\right)\end{array}$ & $\begin{array}{l}\text { Final }^{b} \\
\left(C_{\mathrm{F}}\right)\end{array}$ & & & \\
\hline $\mathrm{p}\left(\mathrm{HPMA}_{50^{-}} \mathrm{CO}^{-}\right.$ & 10 & 2 & 0.2 & 83 & 0.111 \\
\hline \multirow[t]{3}{*}{$\mathrm{EGDMA}_{0.8}$ ) } & 10 & 0.1 & 0.01 & 76 & 0.114 \\
\hline & 5 & 1 & 0.2 & 66 & 0.190 \\
\hline & 5 & 0.05 & 0.01 & 62 & 0.216 \\
\hline $\mathrm{G}_{1}-\left(\mathrm{HPMA}_{50}-\mathrm{CO}-\right.$ & 10 & 2 & 0.2 & 86 & 0.110 \\
\hline \multirow[t]{3}{*}{$\left.\mathrm{EGDMA}_{0.8}\right)$} & 10 & 0.1 & 0.01 & 91 & 0.101 \\
\hline & 5 & 1 & 0.2 & 64 & 0.130 \\
\hline & 5 & 0.05 & 0.01 & 67 & 0.160 \\
\hline $\mathrm{G}_{2}-\left(\mathrm{HPMA}_{50}-\mathrm{CO}-\right.$ & 10 & 2 & 0.2 & 106 & 0.083 \\
\hline \multirow[t]{3}{*}{ EGDMA $\left._{0.8}\right)$} & 10 & 0.1 & 0.01 & 134 & 0.064 \\
\hline & 5 & 1 & 0.2 & 81 & 0.083 \\
\hline & 5 & 0.05 & 0.01 & 93 & 0.071 \\
\hline
\end{tabular}

little measureable difference over two years storage at ambient temperature (ESI, Fig. S22†). The effect of varying the initial polymer concentration in THF can be seen when comparing the nanoparticles generated at identical dilution factors $\left(C_{\mathrm{F}} / C_{\mathrm{I}}\right)$. Higher $C_{\mathrm{I}}$ generally formed larger materials at each dilution factor and higher dilution factors generally formed larger nanoparticles (Table 3).

Scanning electron microscopy (SEM) of branched polymer nanoparticles. The nanoparticles produced during the hexane addition to acetone solutions, and after THF removal from the aqueous nanoprecipitations (ESI; Fig. S23 $\dagger$ ), were studied by SEM.

The controlled addition of hexane allowed samples to be taken at varying volume fractions to observe the nanoparticle formation. An example of this study is shown in Fig. 4A-D for the self-assembly of $\mathrm{G}_{2}$-(HPMA $\left.\mathrm{HO}_{50}-\mathrm{Co}-\mathrm{EGDMA}_{0.8}\right)$. Images of the dried acetone-hexane mixtures at a $\Phi_{\text {hexane }}=0.090$ (Fig. $4 \mathrm{~A}$ ) showed very little structured material and particles resembling uncontrolled aggregates. At an increased $\Phi_{\text {hexane }}=0.286 \mathrm{a}$ higher quantity of poorly-shaped material was observed (Fig. 4B), however, at $\Phi_{\text {hexane }}=0.500$ very distinct spherical nanoparticles were readily observed (Fig. 4C) which are essentially unchanged at $\Phi_{\text {hexane }}=0.800$ (Fig. 4D). The nanoparticles were generally seen to be separate structures although some aggregated nanoparticles were observed (Fig. 4C), possibly as an artefact of sample preparation.

The aqueous nanoprecipitation of $\mathrm{p}\left(\mathrm{HPMA}_{50}-\mathrm{Co}-\mathrm{EGDMA}_{0.8}\right)$ has been shown previously to be observable using SEM, ${ }^{48}$ with clearly distinguishable nanoparticles within highly concentrated areas, presumably formed during the drying of the aqueous continuous phase of the nanodispersion. An example of a typical SEM image of $\mathrm{G}_{2}$-(HPMA $\mathrm{H}_{50}$ - $\mathrm{Co}$-EGDMA $\left.\mathrm{E}_{0.8}\right)$ is shown in Fig. $4 \mathrm{E}$, generated from addition of a THF solution $\left(C_{\mathrm{I}}=5 \mathrm{mg} \mathrm{mL}{ }^{-1}\right)$ 

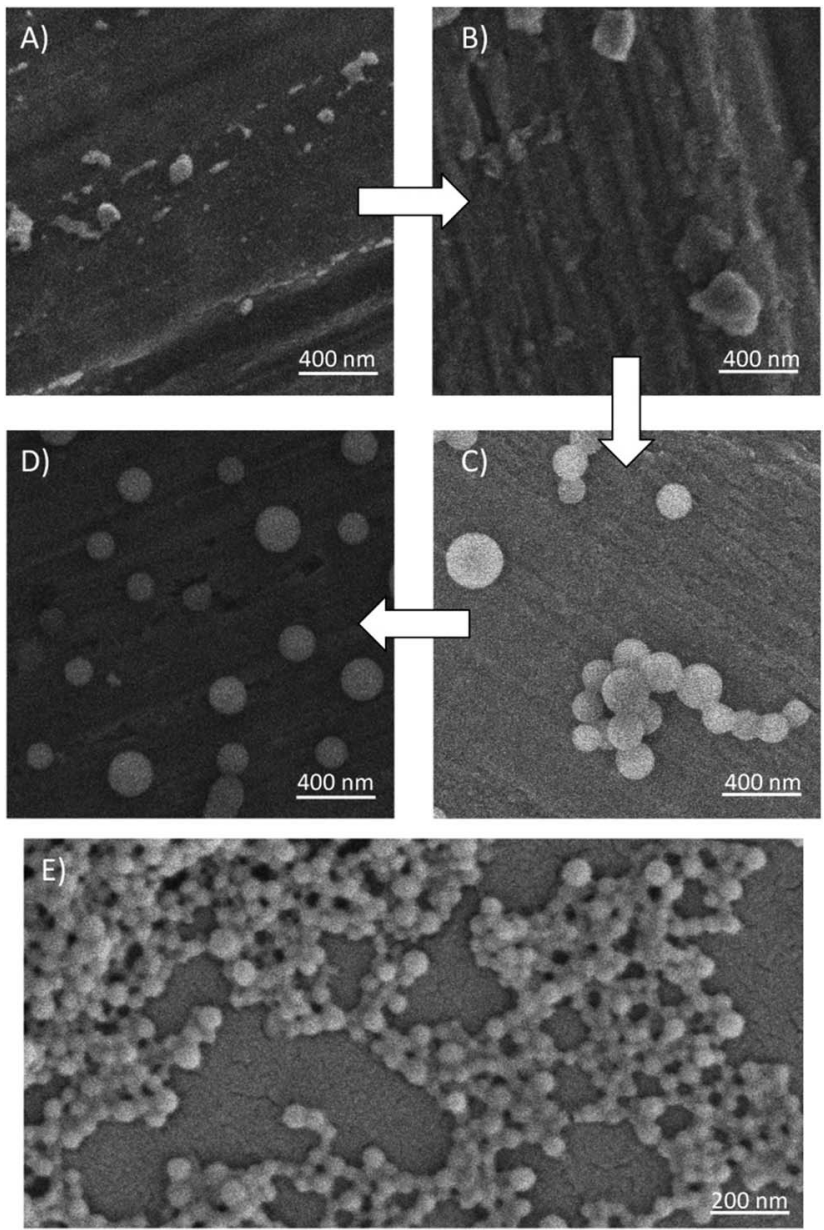

Fig. 4 Scanning electron microscopy of self-assembled nanoparticles from $\mathrm{G}_{2}-\left(\mathrm{HPMA}_{50}-\mathrm{CO}-\mathrm{EGDMA}_{0.8}\right)$. Hexane addition to acetone solutions with solvent fractions of: (A) $\Phi_{\text {hexane }}=0.090$, (B) $\Phi_{\text {hexane }}=0.286$, (C) $\Phi_{\text {hexane }}=0.500$, and (D) $\Phi_{\text {hexane }}=0.800$. (E) Nanoparticles generated by aqueous nanoprecipitation from a THF solution $\left(C_{1}=5\right.$ $\mathrm{mg} \mathrm{mL}^{-1}$ ) an aqueous concentration of $C_{\mathrm{F}}=1 \mathrm{mg} \mathrm{mL}^{-1}$.

to water to form a $C_{\mathrm{F}}=1 \mathrm{mg} \mathrm{mL} \mathrm{m}^{-1}$ (dilution factor $=0.2$ ) after THF removal. The highly concentrated areas of nanoparticles were observed in all cases and dilution of the sample prior to drying did not significantly affect the ability to generate images of distinct and separate nanoparticles.

Self-assembly mechanism of hyp-polydendrons under antisolvent conditions. Nanoprecipitation of linear polymers ${ }^{49}$ has been reported for several years and predominantly utilised to generate uniform spherical nanoparticles from biodegradable polymers. ${ }^{50}$ Although the mechanism of nanoprecipitation is not fully understood, a nucleation/aggregation process ${ }^{51}$ is proposed with size control achieved through a combination of polymer solubility, solvent, polymer concentration in the solvent, viscosity and varying factors affecting the final nanoparticle colloidal stability. ${ }^{52}$ Nanoprecipitation has recently focussed on a broader range of synthetic polymers, such as branched polymer architectures, ${ }^{48}$ and preparation optimisation using flash nanoprecipitation, ${ }^{52}$ microfluidics, ${ }^{53}$ and high throughput automated approaches. ${ }^{54}$
Nanomedicines formed by careful control of linear polymer structure, and nanoprecipitation within the $100-200 \mathrm{~nm}$ size range, ${ }^{55,56}$ have shown high drug loadings and targeting aided by aptamer functionality (the so-called Accurins ${ }^{\mathrm{TM}}$ ). Positive phase I evaluation of Accurins have recently led to progression to phase II human studies with the ability to target delivery to sites of prostate and lung cancer. ${ }^{56,57}$

The new architectures generated during this current study also appear to self-assemble through a nucleation/aggregation mechanism, although further work is required to confirm this. We speculate that the studies of hexane addition to acetone solutions of the branched polymers (Fig. 3A) initially show a high molecular weight expanded coils in solution and the decrease in diameter observed for all study materials demonstrates a steady decrease in the branched core p(HPMA) solvation, forming an increasingly dense structure (shown schematically in Fig. 5Ai-iii). The nuclei that form under these conditions are stable until a critical density or size, leading to a sudden increase in the observed diameter (Fig. 3A) as they aggregate to form larger structures (Fig. 5Aiii-v). These larger

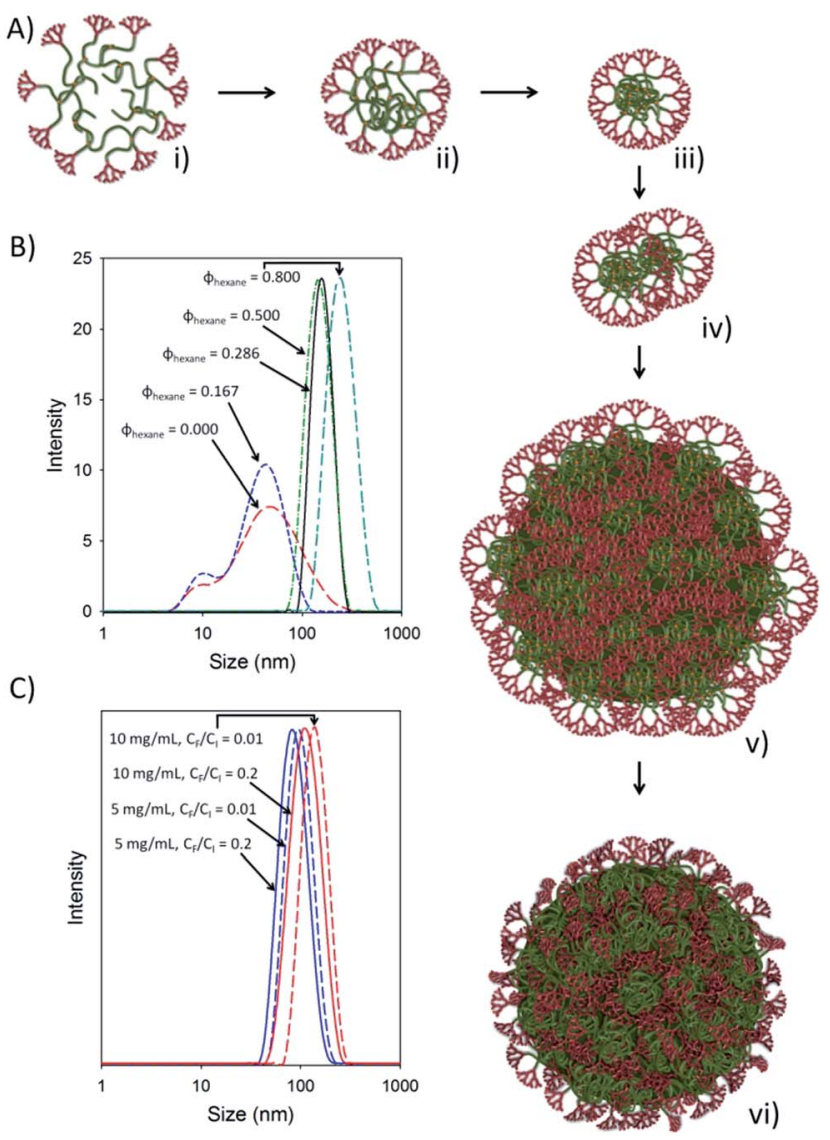

Fig. 5 Proposed mechanism for hyp-polydendron self-assembly and nanoprecipitation: (A) progressive collapse of solvated hyp-polydendrons to form nuclei ( $\mathrm{i}-\mathrm{iii}$ ) and subsequent assembly to form swollen assemblies (iii-v) which finally desolvate and decrease slightly in hydrodynamic diameter (vi). (B) Dynamic light scattering showing the impact of $\Phi_{\text {hexane }}$ on the observed DLS size distributions; (C) DLS measurements of aqueous hyp-polydendron nanoprecipitates formed from varying THF concentrations and different dilutions. 
structures appear to be somewhat swollen within the solvent environment (Fig. 5v) and steadily decrease in size to form more dense nanoparticles in the progressively poorer solvent environment (Fig. $5 \mathrm{v}$-vi) before aggregating to precipitate.

This behaviour is quite clearly seen in the DLS measurements taken at different ratios of acetone and hexane (Fig. 5B). The initially swollen and solvated hyp-polydendrons show appreciable scattering when studied before hexane addition and a broad size distribution is seen with two distinct populations. Addition of a small volume of hexane leads to a narrowing of this distribution and enhanced scattering, with the complete disappearance of this material in later DLS measurements at higher hexane fractions and sharp monomodal peaks for the assembled structures (Fig. 5B). The effect of nanoprecipitation into water using varying $C_{\mathrm{I}}$ values, is also readily seen when overlaying DLS traces (Fig. 5C). It is clear that higher $C_{\mathrm{I}}$ values lead to larger nanoparticle assemblies and higher dilutions $\left(C_{\mathrm{F}} / C_{\mathrm{I}}\right)$ produce larger nanoparticles when using hyp-polydendrons. This is counter to our previous nanoprecipitation reports of branched $\mathrm{p}\left(\mathrm{HPMA}_{x}\right)$ (using EBiBr and ATRP) where, consistently and across different primary chain lengths, higher dilutions produced smaller nanoparticles - also seen in this study (Table $3)$. The dendritic end-group of the primary chain appears, therefore, to influence the nucleation/aggregation mechanism and further work will study this in more detail.

The impact of the generation of the dendron chain ends of the hyp-polydendrons can also be observed within the nanoparticle diameters that are formed during this process. The larger chain ends lead to increased nanoparticle diameters, providing both a new strategy for controlling nanoprecipitation (previously unexplored) and an option for placing considerable functionality at the surface of the nanoparticles that are formed. The branched architectures also provide opportunities that are clearly not available from the linear polymer 'equivalent' structures, although it is important to note that the branched polymers have considerably higher molecular weights and therefore the formation of nuclei is expected to be a more efficient process as the desolvation of a single molecule of a branched polymer will form a larger nucleus than single chain collapse; the weight average structures of the branched polymers comprise $>60$ primary polymer chains.

The acetone-hexane studies have indicated a nucleation/ aggregation/desolvation mechanism which also is intuitively correct for the aqueous nanoprecipitation although the process of THF solution addition to water was conducted extremely quickly and no intermediate structures were studied. The rapid diffusion of the THF into the surrounding water would lead to a desolvation of the expanded structures at the rapidly retreating good-solvent/anti-solvent interface with collapse and aggregation of nuclei to form the large nanoprecipitated aggregates. The influence of the chain end is also apparent, again offering additional options for functionalisation in aqueous systems and size control. The stability of branched nanoprecipitates has previously been attributed to a combination of negative surface charge and branched architecture ${ }^{48}$ and the nanoprecipitates formed in this study also exhibit a negative zeta potential ranging from -57 to $-63 \mathrm{mV}$ for linear polymers and -31 to
-65 $\mathrm{mV}$ for branched polymer nanoprecipitates (values relate to specific nanoprecipitation conditions: $C_{\mathrm{I}}=5 \mathrm{mg} \mathrm{mL}^{-1} ; C_{\mathrm{F}}=1$ $\left.\mathrm{mg} \mathrm{mL}^{-1}\right)$.

Initial guest-host encapsulation studies during aqueous nanoprecipitation. As mentioned above, nanoprecipitation of varying polymers into water has been used to encapsulate a range of guest materials, including small molecules and quantum dots, for nanomedicine evaluation. ${ }^{\mathbf{4 8 b , 5 0 , 5 5}}$ Preliminary studies of hyp-polydendron guest-host behaviour have, therefore, been undertaken to assess the potential for small molecule encapsulation.

Pyrene and Nile Red were simply dissolved within THF along with the $\mathrm{G}_{2}$-(HPMA ${ }_{50}-$ co-EGDMA $\left.{ }_{0.8}\right)$ polymer and subsequently
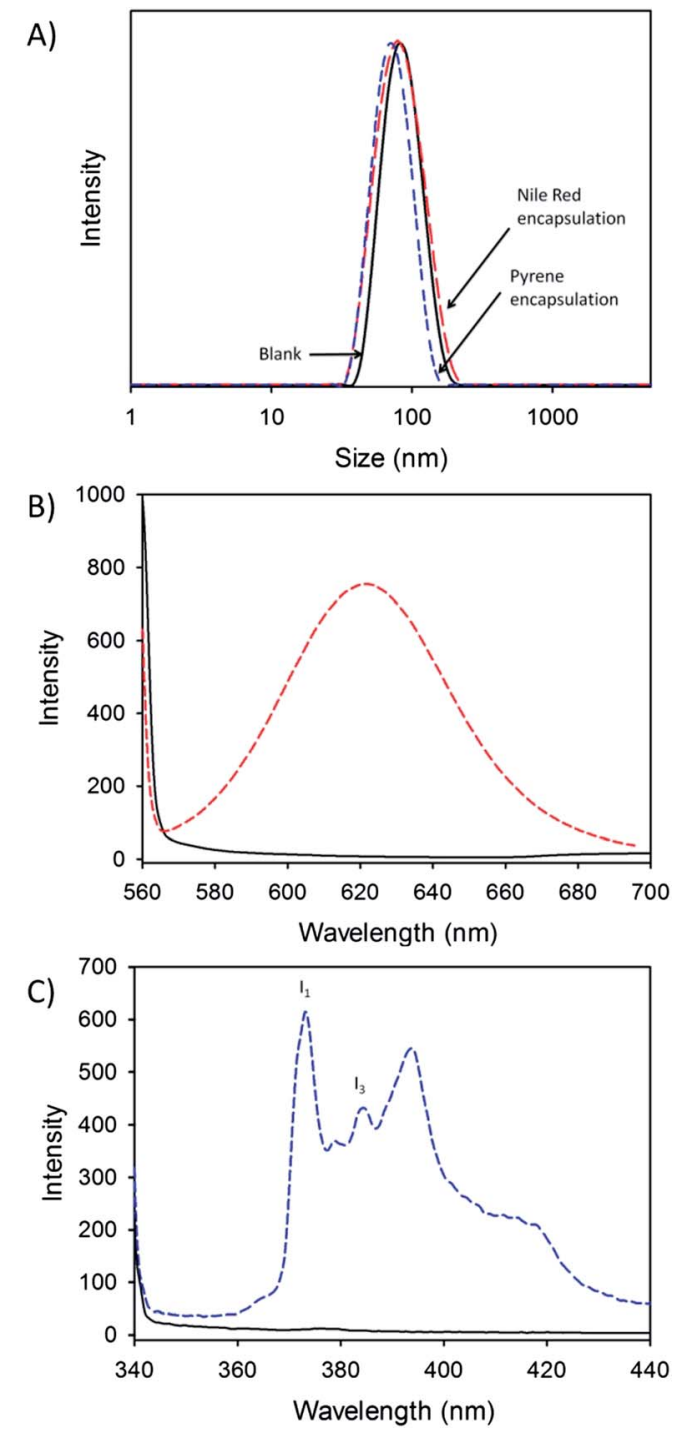

Fig. 6 Encapsulation of guest molecules during $\mathrm{G}_{2}-\left(\mathrm{HPMA}_{50}-\mathrm{CO}-\right.$ $E_{G D M A_{0.8}}$ ) hyp-polydendron nanoprecipitation into water: (A) DLS measurements of empty nanoprecipitates (black solid line), Nile Red containing nanoprecipitates (red long dashed line) and pyrene (blue short dashed line). (B) Fluorescence spectroscopy of Nile Red loaded nanoprecipitates (red dashed line) vs. unloaded nanoprecipitates. (C) Fluorescence spectroscopy of pyrene loaded nanoprecipitates (blue dashed line) vs. unloaded nanoprecipitates. 
nanoprecipitated following the identical process as described previously for a $5 \mathrm{mg} \mathrm{mL}^{-1}$ to $1 \mathrm{mg} \mathrm{mL}^{-1}$ dilution (see ESI $\dagger$ ); in these explorative studies, a low level of each guest molecule $(0.1$ w/w\%) was utilised. Very small decreases in $D_{z}$ were observed when the guest molecules were present, with the empty nanoprecipitates showing diameters of $81 \mathrm{~nm}$ and Nile Red and pyrene encapsulation leading to $D_{z}=76$ and $69 \mathrm{~nm}$ respectively (Fig. 6A). Narrow dispersities were maintained $\left(\mathrm{PDI}_{\text {blank }}=\right.$ $\left.0.083 ; \mathrm{PDI}_{\text {Nile Red }}=0.109 ; \mathrm{PDI}_{\text {pyrene }}=0.061\right)$ across the samples.

Fluorimetric analysis of the aqueous nanoparticles in the absence and presence of the guest molecules was conducted. The blank hyp-polydendron nanoprecipitates showed no measureable fluorescence when excited at either $552 \mathrm{~nm}$ or 335 $\mathrm{nm}$; however, a clear fluorescence was observed from both samples contained the hydrophobic probes when using the appropriate excitation conditions (Fig. 6B and C). The fluorescence observed from Nile Red $(630 \mathrm{~nm})$ clearly indicates that the dye guest molecule is present within a hydrophobic environment and has been encapsulated during nanoprecipitation. ${ }^{58}$ The fine structure of the fluorescence from the encapsulated pyrene allows an indication of the polarity of the immediate environment within the nanoparticle. The ratio of the intensities of the first and third vibrational bands ${ }^{59}\left(I_{1} / I_{3}\right)$ were measured to be 1.420 , which lies between values associated in the literature with pyrene fluorescence when dissolved in dichloromethane $\left(I_{1} / I_{3}=1.370\right)$ or ethyl acetate $\left(I_{1} / I_{3}=1.449\right) .{ }^{60}$

\section{Conclusions}

Collectively, we report the first syntheses of a new polymer architecture (hyperbranched polydendrons), a comparison of the behaviour of the linear-dendritic hybrids that form the primary chains of the new architecture, and the antisolventdriven self-assembly and encapsulation of the branched polymers to form nanoparticles. The nanoparticles display remarkable size control, stability and uniformity of behaviour despite their combined very high molecular weight and dispersity. The ability to modify the self-assembly through endgroup dendron generation, and formation of materials with diameters $>100 \mathrm{~nm}$, opens avenues of research for dendronfunctional materials at much higher particle sizes and increased synthetic ease than previously described through conventional dendrimer or hyperbranched materials. This report therefore offers a straight-forward strategy for exploring the effects of the architectural components of hyp-polydendrons and their application within fields that have conventionally evaluated dendrimers and nanoprecipitates. Further reports will extend this platform including the optimisation of guest molecule loading, studies of biological interactions with cells and structural component modification to allow increased behavioural control.

\section{Acknowledgements}

The authors wish to thank the Engineering and Physical Sciences Research Council for a PhD studentship (FL) and grant funding (EP/I038721/1) that underpinned the research. The
University of Liverpool and the Centre for Materials Discovery at Liverpool is also gratefully acknowledged for access to scanning electron microscopy.

\section{Notes and references}

1 E. Rizzardo and D. H. Solomon, Aust. J. Chem., 2012, 65, 945.

2 K. Matyjaszewski, Macromolecules, 2012, 45, 4015.

3 B. I. Voit and A. Lederer, Chem. Rev., 2009, 109, 5924.

4 D. G. van der Poll, H. M. Kieler-Ferguson, W. C. Floyd, S. J. Guillaudeu, K. Jerger, F. C. Szoka and J. M. Fréchet, Bioconjugate Chem., 2010, 21, 764.

5 T. M. Hermans, M. A. C. Broeren, N. Gomopoulos, P. van der Schoot, M. H. P. van Genderen, N. A. J. M. Sommerdijk, G. Fytas and E. W. Meijer, Nat. Nanotechnol., 2009, 4, 721.

6 A. Stoddart, W. J. Feast and S. P. Rannard, Soft Matter, 2012, 8, 1096.

7 S. P. Rannard, N. J. Davis and I. Herbert, Macromolecules, 2004, 37, 9418.

8 S. Grayson and J. M. J. Fréchet, Org. Lett., 2002, 4, 3171.

9 A. Carlmark, E. Malmström and M. Malkoch, Chem. Soc. Rev., 2013, 42, 5858.

10 S. P. Rannard and N. J. Davis, J. Am. Chem. Soc., 2000, 122, 11729.

11 S. Rannard, N. Davis and H. McFarland, Polym. Int., 2000, 49, 1002.

12 F. Aulenta, M. G. B. Drew, A. Foster, W. Hayes, S. Rannard, D. W. Thornthwaite, D. R. Worrall and T. G. A. Youngs, J. Org. Chem., 2005, 70, 63.

13 M. S. Diallo, L. Balogh, A. Shafagati, J. H. Johnson, W. A. Goddard and D. A. Tomalia, Environ. Sci. Technol., 1999, 33, 820.

14 P. Ortega, M. J. Serramia, M. A. Munoz-Fernandez, F. J. de la Mata and R. Gomez, Tetrahedron, 2010, 66, 3326.

15 N. Larson and H. Ghandehari, Chem. Mater., 2012, 24, 840.

16 C. C. Lee, J. A. MacKay, J. M. J. Fréchet and F. Szoka, Nat. Biotechnol., 2005, 23, 1517.

17 C.-L. Liu, C.-H. Lin, C.-C. Kuo, S.-T. Lin and W.-C. Chen, Prog. Polym. Sci., 2011, 36, 603.

18 C. P. Rhodes, J. W. Long, K. A. Pettigrew, R. M. Stroud and D. R. Rolison, Nanoscale, 2011, 3, 1731.

19 Y. Yang and M. W. Urban, Chem. Soc. Rev., 2013, 42, 7446. 20 Y. Chen, Macromolecules, 2012, 45, 2619.

21 J. P. Rao and K. E. Geckeler, Prog. Polym. Sci., 2011, 36, 887. 22 A. O. Moughton, M. A. Hillmyer and T. P. Lodge, Macromolecules, 2012, 45, 2.

23 L. N. Pilon, S. P. Armes, P. Findlay and S. P. Rannard, Eur. Polym. J., 2006, 42, 1487.

24 H. Wang, L. Chen, Y. Feng and H. Chen, Acc. Chem. Res., 2013, 46, 1636.

25 R. B. Grubbs and Z. Sun, Chem. Soc. Rev., 2013, 42, 7436.

26 Z.-Y. Qiao, R. Ji, X.-N. Huang, F.-S. Du, R. Zhang, D.-H. Liang and Z.-C. Li, Biomacromolecules, 2013, 14, 1555.

27 W. Li, Y. Kim and M. Lee, Nanoscale, 2013, 5, 7711.

28 L. A. Fielding, M. J. Derry, V. Ladmiral, J. Rosselgong, A. M. Rodrigues, L. P. D. Ratcliffe, S. Sugihara and S. P. Armes, Chem. Sci., 2013, 4, 2081. 
29 S. M. Grayson and J. M. J. Fréchet, Chem. Rev., 2001, 101, 3819.

30 L. Röglin, E. H. M. Lempens and E. W. Meijer, Angew. Chem., Int. Ed., 2011, 50, 102.

31 D. Astruc, E. Boisselier and C. Ornelas, Chem. Rev., 2010, 110, 1857.

32 (a) J. M. Oliveira, A. J. Salgado, N. Sousa, J. F. Mano and R. L. Reis, Prog. Polym. Sci., 2010, 35, 1163; (b) A. Nazemi, S. M. M. Haeryfar and E. R. Gillies, Langmuir, 2013, 29, 6420; (c) C. Lee, S.-T. Lo, J. Lim, V. C. P. da Costa, S. Ramezani, O. K. Öz, G. M. Pavan, O. Annunziata, X. Sun and E. E. Simanek, Mol. Pharmaceutics, 2013, 10, 4452; (d) H. S. Oberoia, N. V. Nukolovab, A. V. Kabanov and T. K. Bronicha, Adv. Drug Delivery Rev., 2013, 65, 1667; (e) G. M. Ryan, L. M. Kaminskas, J. B. Bulitta, M. P. McIntosh, D. J. Owen and C. J. H. Porter, J. Controlled Release, 2013, $172,128$.

33 L. M. Bronstein and Z. B. Shifrina, Chem. Rev., 2011, 111, 5301.

34 A. R. Menjoge, R. M. Kannan and D. A. Tomalia, Drug Discovery Today, 2010, 15, 171.

35 J. Lim, M. Kostiainen, J. Maly, V. C. P. da Costa, O. Annunziata, G. M. Pavan and E. E. Simanek, J. Am. Chem. Soc., 2013, 135, 4660.

36 (a) M. V. Walter, P. Lundberg, A. Hult and M. Malkoch, J. Polym. Sci., Part A: Polym. Chem., 2011, 49, 2990; (b) L. A. Connal, R. Vestberg, C. J. Hawker and G. G. Qiao, Macromolecules, 2007, 40, 7855.

37 Y. Chang and C. Kim, J. Polym. Sci., Part A: Polym. Chem., 2001, 39, 918.

38 N. O'Brien, A. McKee, D. C. Sherrington, A. T. Slark and A. Titterton, Polymer, 2000, 41, 6027.

39 S. Graham, S. P. Rannard, P. A. G. Cormack and D. C. Sherrington, J. Mater. Chem., 2007, 17, 545.

40 J. Weaver, R. Williams, P. Findlay, B. Royles, A. I. Cooper and S. P. Rannard, Soft Matter, 2008, 4, 985.

41 T. He, D. J. Adams, M. F. Butler, A. I. Cooper and S. P. Rannard, J. Am. Chem. Soc., 2009, 131, 1495.

42 T. He, D. J. Adams, M. F. Butler, C. T. Yeoh, A. I. Cooper and S. P. Rannard, Angew. Chem., Int. Ed., 2007, 46, 9243.
43 J. V. M. Weaver, S. P. Rannard and A. I. Cooper, Angew. Chem., Int. Ed., 2009, 48, 2131.

44 T. Kaneko, T. Horie, M. Asano, T. Aoki and E. Oikawa, Macromolecules, 1997, 30, 3118.

45 J. M. J. Fréchet, M. Henmi, I. Gitsov, S. Aoshima, M. R. Leduc and R. B. Grubbs, Science, 1995, 269, 1080.

46 H. C. Kolb, M. G. Finn and K. B. Sharpless, Angew. Chem., Int. Ed., 2001, 40, 2004.

47 S. P. Rannard and N. J. Davis, Org. Lett., 2000, 2, 2117.

48 (a) R. A. Slater, T. O. McDonald, D. J. Adams, E. R. Draper, J. V. M. Weaver and S. P. Rannard, Soft Matter, 2012, 8, 9816; (b) T. Betancourt, B. Brown and L. Brannon-Peppas, Nanomedicine, 2007, 2, 219.

49 O. Thioune, H. Fessi, J. P. Devissaguet and F. Puisieux, Int. J. Pharm., 1997, 146, 233.

50 S. Schubert, J. T. Delaney and U. S. Schubert, Soft Matter, 2011, 7, 1581.

51 V. K. Lamer and R. H. Dinegar, J. Am. Chem. Soc., 1950, 72, 4847.

52 C. Zhang, V. J. Pansare, R. K. Prud'homme and R. D. Priestly, Soft Matter, 2012, 8, 86.

53 R. Karnik, F. Gu, P. Basto, C. Cannizzaro, L. Dean, W. KyeiManu, R. Langer and O. C. Farokhzad, Nano Lett., 2008, 8, 2906.

54 I. Y. Perevyazko, J. T. Delaney, A. Vollrath, G. M. Pavlov, S. Schubert and U. S. Schubert, Soft Matter, 2011, 7, 5030 .

55 P. M. Valencia, P. A. Basto, L. Zhang, M. Rhee, R. Langer, O. C. Farokhzad and R. Karnik, ACS Nano, 2010, 4, 1671.

56 J. Cheng, B. A. Teply, I. Sherifi, J. Sung, G. Luther, F. X. Gu, E. Levy-Nissenbaum, A. F. Radovic-Moreno, R. Langer and O. C. Farokhzad, Biomaterials, 2007, 28, 869-876.

57 J. Shi, Z. Xiao, N. Kamaly and O. C. Farokhzad, Acc. Chem. Res., 2011, 44, 1123.

58 D. L. Sackett and J. Wolff, Anal. Biochem., 1987, 167, 228.

59 D. López-Díaz and M. M. Velázquez, Chem. Educ., 2007, 12, 327.

60 K. Kalyanasundaram and J. K. Thomas, J. Am. Chem. Soc., 1977, 99, 2039. 